\title{
COMPORTAMENTO DOS CROMOSSOMIOS SEXUAIS DO Dysdercus mendesi NA SEGUNDA DIVISÃO DOS ESPERMATÓCITOS
}

S. de Toledo Piza Jor.

Em meu trabalho anterior (3) dei o resultado de minhas primeiras observações relativas aos cromossômios dos Hemípteros do gênero Dysdercus, referindo-me a três das nossas espécies mais comuns, ou sejam : Dysdercus ruficollis (L.), Dysdercus honestus Blöte e Dysdercus mendesi Blöte. Dei uma descrição abreviada daquilo que me pareceu essencial para o suporte dos pontos de vista que venho sustentando a respeito da dicentricidade dos cromossômios, os quais têm sido por mim considerados como isocromossômios providos de um cinetocore na extremidade de cada braço $(\mathbf{1}, \mathbf{2})$.

Quase todos os trabalhos que tenho publicado sôbre o assunto, quer pelo caráter especial do objetivo visado, quer pela escassez do material à disposiçâo, têm sido apresentados como breves notícias, primeiras observaçōes ou notas ureliminares, ficando para mais tarde o estudo detalhado de outros aspectos, para o que continuo preparando e colecionando material.

Relativamente a Dysdercus mendesi, espécie que considerei como a mais interessante das três, dei apenas breves informações quanto ao número e ao comportamento dos autossômios na espermatogênese e assinalei a presença de dois sexo-cromossômios, procurando mostrar que êsses elementos, providos de forte constrição mediana, dividiam-se transversalmente, tornando-se monocêntricos, para depois se unirem, no final da anáfase primária, e em seguida separarem-se, de maneira que cada espermatídio recebesse um elemento sexual, ou seja, uma das metades dos cromossômios iniciais. Assim sendo, os heterocromossômios continuariam monocêntricos para, na espermiogênese, readquirirem a dicentricidade com que se apresentam na metáfase primária. Também me referi à curvatura dos cromossômios nas anáfases somáticas, o que veio confirmar observações já efetuadas com outras espécies de Hemípteros.

Aspectos vários, considerados de importância, anotados, porém não referidos, fizeram com que eu recorresse mais uma vez ao distinto entomólogo de Campinas, Dr. Luiz O. Teixeira Mendes, para a obtenção de mais algum

(*) Da Escola Superior de Agricultura "I uiz de Queiroz" da Iniveridade de S. Paulo. 
material. De posse dêste, tratei logo de preparar algumas lâminas, que foram guardadas para ulterior exame.

Há dias, tive o prazer de receber a visita daquele prezado colega, o qual me comunicou que, havendo examinado em preparações de orceína acética abundante máterial de Dysdercus mendesi, constatara que, ao con-

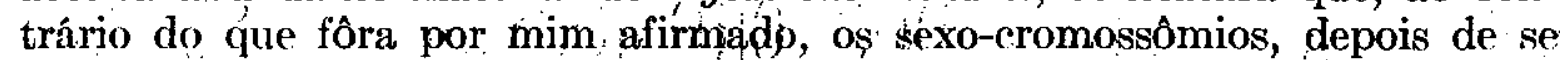
juntarem, da maneira descrita, no final da anáfase, não mais se separavam e sim se fundiam num elementáfíniço, que passava em precessão para um dos pólos.

Reexaminando as lâminas em que fiz as minhas primeiras observações, constatei que outra não podia ter 'kidó a conclusăo, porquanto a escassez de espermatócitos secundários em divisão nenhuma informação me dera acêrca da verdadeira conduta dos cromossômios sexuais. Entretanto, a presença do sexo-cromossômio na placa equatorial de uma metáfase secundária, a falsa interpretação de alguns aspectos duvidosos e, sobretudo, o fato de se conhecerem cromossômiós sexuais que se comportam na primeira divisão exatamente da maneira por mim deserita, separando-se na segunda (Oncopeltus), levaram-me a admitir essa conduta no caso do Dysdercus mendesi. Estudando, porém, as lâminas preparadas por último, verifiquei que o Dr. Luiz O. Teixeira Mendes tem tôda razão, pois que, de fato, uma vez unidos no final da anáfase primária os sexo-cromossômios permanecem como uma unidade morfológica, passando para uma das células resultantes da segunda divisão. Embora o heterocromossômio tenha sido sempre encontrado em precessão, a sua presença nó equador das metáfases secundárias, poucas vêzes assinalada, fala em favor da possibilidade de se vir a encontrar êsise elemento também enr sincrơnismo e sucessão. Nesse material pude observar espernatídios relativamente jovens com o sexo-cromossômio, ao lado de outros destituídos daquéle elemento.

A natureza composta dos cromóossômios sexuais do Dysdercus mendesi, o comportamento, a mieu ver único, dêtsses elementos e algumas outras partirularidades já observadas nò méu primeiro material estão a aconselhar um estudo aprofundado da meiose nos dois sexos dessa interessantíssima espérie. Aliás, era êsse o meu intuito; como se pode depreender da natureza do meu artigo anterior, qué nấo passa de uma nota prévia, na qual nem ao menos foi feita referência à literratura sôbre o assunto. Informado, porém, pelo meu distinto àmigo de que pretende êle publicar uma série de artigos sôbre a ńeiose do Dysdercus, dẹixarei para ocasião oportuna o prosseguimentó dé meus estudos sôbre tão interessante questão.

\section{SÜ M M A R Y}

In a previous publication (3) the author described the behaviour of the sex-chromosomes of Dysdercus mendesi Blöte. Following conversation with Dr. Luiz O. T. Mendes, the author was stimulated to reexamine the slides and to study another new series of lices. As a result of these observations the writer now concludes that in the division of the 2nd spermatocyte: the sex-chromosomes pass undivided to one pole. Thus half of the spe "matids rencives $c$ single compound element and half receives none. This is believed to bes imilar to the ronclusions rezched by. Dr. Luiz $O$. T. Mendes. Further studies will be made with respe't to the nature of the compound element. 


\section{LITERATURA CITADA}

1. Piza, S. de Toledo. Comportamento dos cromossomios na meiose de Euryophthalmus rufipennis Laporte (IIemiptera-Pyrrhocoridae). An. Lsc. Sup. Agric. "Luiz de Queiroz" 3: 28-54. 1946.

2. Piza. S. de Toledo. Nota prévia sôbre a meiose de Corizus (Liorhyssus) hyalinus (Fabr.) (Hemiptera-Corizidae). An. Esc. Sup. Agric. "Luiz de Queiroz" 3: $141-148.1946$.

3. Piza, S. de Toledo. Cromossomios de Dysdercus. (Hemiptera-Pyrrhocoridae). An. Esc. Sup. Agric. "laviz de Queiroz" 4: 210-216. 1947. 